\title{
Review \\ Clinical review: The impact of noise on patients' sleep and the effectiveness of noise reduction strategies in intensive care units
}

\author{
Hui Xie ${ }^{1,2}$, Jian Kang ${ }^{1}$ and Gary H Mills ${ }^{2}$
}

1School of Architecture, University of Sheffield, Western Bank, Sheffield S10 2TN, United Kingdom
2Sheffield Teaching Hospitals NHS Foundations Trust, Royal Hallamshire Hospital, Glossop Road, Sheffield S10 2JF, United Kingdom

Corresponding author: Hui Xie, h.xie@sheffield.ac.uk, yanshencun@gmail.com

Published: 9 March 2009

This article is online at http://ccforum.com/content/13/2/208

Critical Care 2009, 13:208 (doi:10.1186/cc7154)

(c) 2009 BioMed Central Ltd

\begin{abstract}
Excessive noise is becoming a significant problem for intensive care units (ICUs). This paper first reviews the impact of noise on patients' sleep in ICUs. Five previous studies have demonstrated such impacts, whereas six other studies have shown other factors to be more important. Staff conversation and alarms are generally regarded as the most disturbing noises for patients' sleep in ICUs. Most research in this area has focused purely on noise level, but work has been very limited on the relationships between sleep quality and other acoustic parameters, including spectrum and reverberation time. Sound-absorbing treatment is a relatively effective noise reduction strategy, whereas sound masking appears to be the most effective technique for improving sleep. For future research, there should be close collaboration between medical researchers and acousticians.
\end{abstract}

\section{Introduction}

Noise, defined as unwanted sounds, could affect people both psychologically and physiologically [1], with reported negative effects including cardiovascular stimulation, hearing loss, increased gastric secretion, pituitary and adrenal gland stimulation, suppression of the immune response to infection, as well as female reproduction and fertility [2-7]. The World Health Organization (WHO) recommended that noise levels inside hospital wards should not exceed $30 \mathrm{dBA}$ at night in terms of sleep disturbance [8]. Unfortunately, most case studies, especially the recent data, show that noise levels inside hospitals are much higher than the guideline values. Since the 1960s, the average noise levels inside hospitals have increased by an average of $0.38 \mathrm{dBA}$ (day) and $0.42 \mathrm{dBA}$ (night) per year [9].

The noise level in intensive care units (ICUs) ranges from 50 to $75 \mathrm{dBA}$, with the highest night peak level even reaching $103 \mathrm{dBA}$ [10]. Sleep disturbance is thus a common problem for patients. Sleep is a complicated and active process. In terms of the measurement of eye movement, sleep is divided into two main types, namely rapid eye movement (REM) and non-rapid eye movement (NREM) sleep. Each type may have a distinct set of associated physiological, psychological and neurological functions.

Numerous general studies have been carried out on the effects of noise on sleep [11-16]. However, many of them are not directly related to the influence of noise on patients' sleep in ICUs. Firstly, healthy subjects, rather than patients, were normally used in most existing studies. Secondly, road/rail/air traffic noise sources were considered, and their acoustic characteristics are rather different from those of the complicated, multiple and dynamic noise sources in ICUs. Thirdly, multiple factors, such as patients' discomfort, pain, as well as lighting and ventilation conditions, would definitely contribute to patients' inability to sleep.

Therefore, the aim of this review paper is to answer the following questions. First, is noise the most disruptive factor to sleep for ICU patients, or is noise only responsible for a small percentage of the sleep disruption? Second, from the patients' point of view, what is the most disturbing noise source for their sleep? Besides the noise level, what are the effects of other room acoustic parameters, such as the noise spectrum and reverberation time (RT), on ICU patients' sleep quality? Third, how effective are the noise reduction strategies/interventions to decrease the sleep disturbance in ICUs?

\section{Methods}

The Cochrane Collaboration method was used for this review. An extensive literature search was conducted using the following electronic databases: MEDLINE (1966 to June 2008), CINAHL (1982 to June 2008), Scopus (1966 to June 2008), Cochrane Library (1991 to June 2008), and ISI Web of Knowledge (1900 to June 2008). The major medical subject heading $(\mathrm{MeSH})$ and text words used in the search 
were: 'sleep', 'sleep disorder', 'sleep deprivation', 'noise' in conjunction with 'intensive care', 'intensive care unit' and 'critical care'. Related references of all identified papers displayed in the above databases were also scanned. To study the effectiveness of noise reduction strategies/interventions, additional search terms were used, including 'spectrum', 'reverberation time', 'sound masking' and 'acoustic absorber'. The searches were restricted to the research literature concerning the relationships between noise and patients' sleep during their hospital stay and published in full in the English language.

Of the 167 papers found by the search strategy, 23 finally met the inclusion criteria. A number of methods have been applied in those studies, including polysomnography, observation, patient self-assessment/questionnaire, and environmental noise recording. Some methods were effectively integrated by the investigators in order to enhance the accuracy and reliability of the research outcomes. Table 1 summarises the characteristics of the key studies.

\section{Importance of noise on sleep disturbance}

Although it has been widely recognised that noise has negative effects upon the sleep of ICU patients, there are some disagreements in the literature on the importance of sleep disturbance from ICU noises, as can be seen in Table 1. Of the 11 selected previous original papers, 6 studies suggest that noise is responsible for only a small proportion of the overall arousals and awakenings from sleep, whilst 5 papers believe that noise is the most significant cause of sleep disturbance. Based on the SPSS statistic analysis, no significant differences were found between the two groups that argue whether or not noise is the major factor in sleep disturbance, in terms of sleep evaluation method, publication year, type of ICU, age of patients, number of patients and duration of stay.

Jones and colleagues [17], according to their questionnaire outcome, indicated that the inability to lie comfortably was the most important factor in preventing patients' sleep, and then pain, noise and anxiety followed subsequently. A largesample survey was conducted by Freedman and colleagues in 1999 [18] to investigate the ICU patient perception of sleep quality and etiology of sleep disruption. They further explained the patients' quick adaptability to ICU noise and noise's inability to cause awakenings as the two possible reasons for the low mean sleep-disruptive scores collected in their study. Meyer [19] also mentioned the same point that patients would gradually be conditioned to environmental noise in ICUs. After continuously monitoring the noise level and performing polysomnography over 24 hours, Freedman and colleagues in 2001 [20] concluded that only $17 \%$ of awakenings and $11.5 \%$ of arousals from sleep under mechanically ventilated conditions were due to the environmental noises. Frisk and Nordstrom [21] found the noise level rated by the patients to be low, which indicated that noise was not the major etiologic factor responsible for sleep disruption in ICUs. Pain was considered to be the commonest reason of disrupted sleep. According to Gabor and colleagues [22], loud noise accounted for $20.9 \%$ of the observed sleep disruption, while the cause of the majority of sleep disturbances under mechanically ventilated conditions remained unknown. According to Ugras and Oztekin [23], 57.6\% of the patients indicated that being in a noisy environment was the second most frequently sleep disturbing factor, only after being kept immobile (63.6\%).

On the other hand, Hilton used polysomnography, continuous investigator observation over 24 hours and patient interviews to identify that most sleep disturbances of selected patients in the respiratory ICU were caused by noise [24]. Aaron and colleagues [25] confirmed a significant correlation with sound peaks over $80 \mathrm{dBA}$ and electroencephalogram arousals from patients' sleep, as well as a significant difference between the number of arousals in quiet periods and that in very loud periods based on the number of noise peaks. In another study, although the sample size was small (nine subjects), the sleep observation together with the continuous recordings of noise and light level enabled Cureton-Lane and Fontaine to determine that noise was the strongest indicator of sleep state. The louder the noise was, the greater the awaking possibility of the children in the pediatric ICU [26]. Richardson and colleagues [27], after examining the impact of earplugs and eye masks on the critical care patients' sleep, found that $58.8 \%$ of the patients in the intervention group and $25 \%$ of the patients in the non-intervention group voted noise as the main factor of their sleep disturbance. Hweidi's [28] research supported that patients interpreted the unfamiliar and loud noises as the major cause preventing them from sleeping during their ICU stay.

\section{The impact of sleep disturbance on patients}

Sleep disturbance is a factor in the development of delirium, as well as producing specific effects on the respiratory, cardiovascular and immunological systems. Critical care patients are especially prone to delirium, as their normal circadian pattern of adrenocorticotropic hormone and melatonin levels is changed markedly by sepsis. Rather than there being a peak of adrenocorticotropic hormone at dawn and an elevation in melatonin levels during the period after midnight (peaking around $3 \mathrm{am}$ ), a flattening of this response is seen. This encourages a disturbance in sleep patterns leading to sleep during the day [29-31] and a reduction in sleep at night as well as general sleep fragmentation, with a reduction in both slow wave sleep and REM sleep. Hallucinations may occur during the transition from wakefulness into NREM sleep and from NREM sleep to wakefulness and are a major problem for critical care patients. Patients may also develop state dissociation disorders, which will appear as hallucinations or as REM sleep behavioural disorders. These episodes promote delusional memories, which in turn increase the likelihood of post-traumatic stress disorder. 


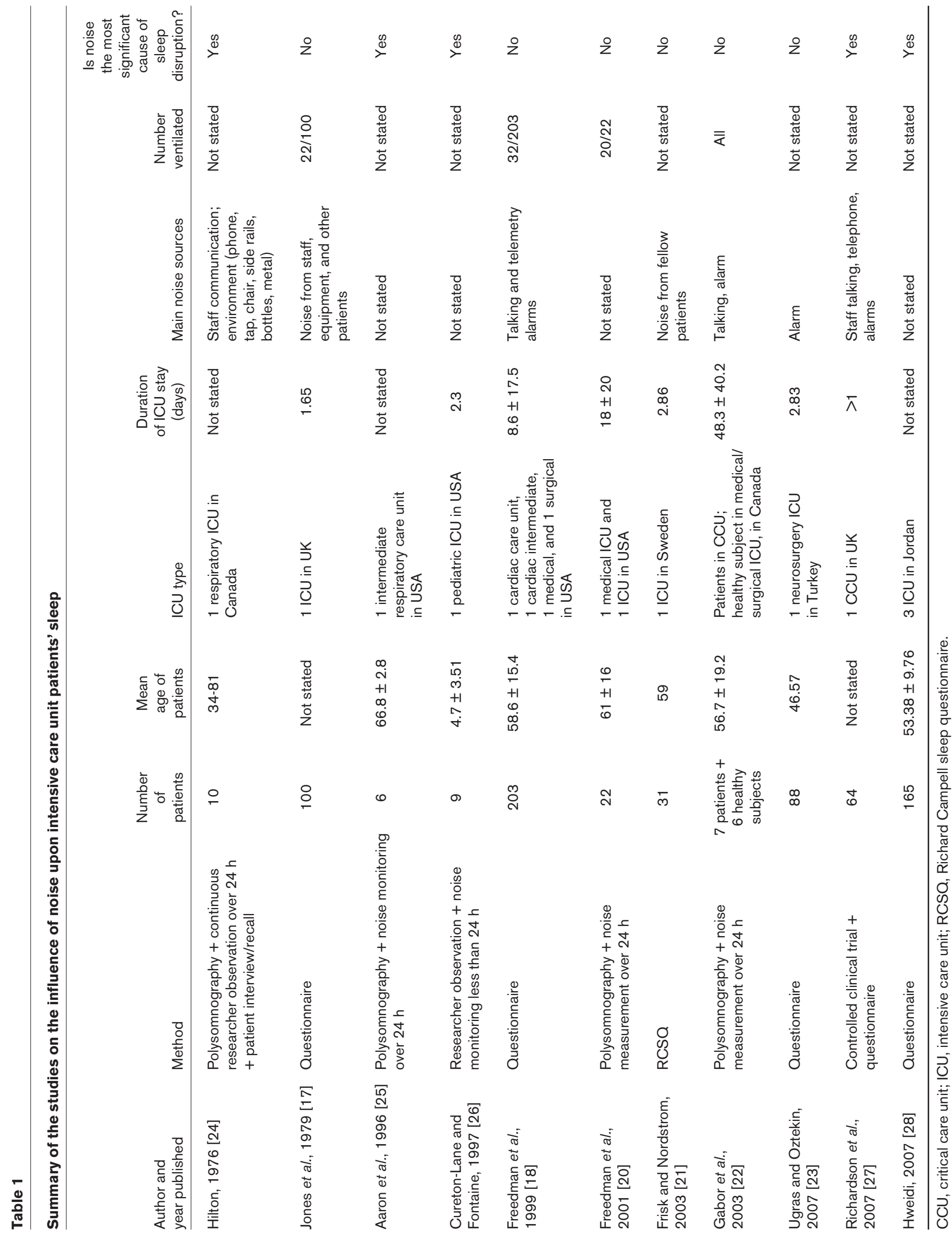


Drugs used in hospital may further aggravate the levels and appropriateness, as well as timing, of either wakefulness or sleep and, on withdrawal (for example opioids), may precipitate a rebound increase in REM sleep, which in itself can precipitate nightmares, hypertension, tachycardia and hypoventilation. Noise will exaggerate these phenomena by triggering a transition from sleep towards wakefulness. All these factors increase the risk of delirium, which may occur in up to $70 \%$ or $80 \%$ of ICU patients [32-33]. Delirium increases length of stay, morbidity and even mortality [33].

Sleep disturbance may also disrupt immune function [34-35]. Two days of sleep deprivation has been shown to impair cellmediated immune reactions as measured by lymphocyte production and adhesiveness [36] and to nullify the beneficial effect of immunisation in mice immunised against the influenza virus [37]. In humans, sleep deprivation increases IL1, IL2 [38], IL6 and tumour necrosis factor levels [39] and probably reduces natural killer cell activity $[34,38,40]$. Cardiovascularly, episodes of increased sympathetic activity may occur during noise disturbance. From a respiratory perspective, increases in REM sleep produce a reduction in ventilatory response to hypoxia and hypercapnia, particularly in the obese, men and those prone to apnoeas. This may also be a problem during weaning from mechanical ventilation [41] as well as a cause of respiratory deterioration towards the end of a critical illness, potentially increasing readmission rates to critical care.

\section{Acoustic characteristics Noise sources}

The major noise sources identified by the previous studies vary from ventilator noise, ventilator alarm, suctioning, heart monitor alarm, nebulizer, pulse oximeter tones and alarm, telephones ringing, air conditioning, television, radio, banging, rubbish bin or trolley noises, intercom, staff bleeps, talking (staff, nurses), visitors, fellow-patients, and general activities $[42,43]$. According to the occurrences in the literature, staff conversation (five papers) and alarm (four papers) seem to be the most disturbing noises for ICU patients' sleep. It is interesting to note that alarms are not usually perceived as helpful by the ICU staff [44].

\section{Noise spectrum}

Sound spectrum, a plotted relationship between frequency and sound level, is important for sound perception [1], whereas in the existing studies the consideration of this facet is very limited. Busch-Vishniac [45] and colleagues showed that the spectra at a pediatric ICU were flat over $63 \mathrm{~Hz}$ to $2 \mathrm{kHz}$, with higher sound levels at lower frequencies, and a gradual roll off above $2 \mathrm{kHz}$. Livera and colleagues [46] analysed the spectrum of equipment and activity noises in the neonatal ICU, showing that the noise was predominant in the range of 1 to $8 \mathrm{kHz}$. Ryherd and colleagues [47] provided detailed information concerning the noise characteristics in a neurological ICU, with the background noise measured in 1/3 octave bands, indicating that high frequency noise dominated in the case study. However, it is noted that none of the three papers studied the impact of noise spectrum on patients' sleep.

\section{Reverberation time}

$\mathrm{RT}$ is an important index to evaluate room acoustics. It is defined as the time taken for a sound to decay $60 \mathrm{~dB}$ after the source has stopped [1]. Blomkvist and colleagues [48] replaced the old sound reflecting ceiling tiles by the sound absorbing tiles in an intensive coronary care unit. The RT was markedly reduced by $0.4 \mathrm{~s}$ in the main working space and $0.5 \mathrm{~s}$ in a patient ward, which had a positive effect, including better general care quality and improved staff working efficiency. MacLeod and colleagues [49] installed the sound absorbing panels made of wrapped fibre-glass and antibacterial fabric on the ceiling and corridor walls in a hematological cancer unit. The reverberation dramatically dropped, and the excessively prolonged RT that had existed in the $800 \mathrm{~Hz} 1 / 3$ octave band was eliminated. While only one of the above two studies was carried out in an ICU, the relationship between sleep disruption and RT was not analysed.

\section{Effectiveness of noise reduction strategies}

Although descriptive studies have defined and increased understanding of noise problems and serious sleep disturbance in ICUs, relatively few interventional studies have been carried out. Interventions that have manifested observable improvements in patients' sleep can be categorised into earplugs, behavioural modification, sound masking, and acoustic absorption. The effectiveness of these interventions is compared in Table 2. The average noise level reduction and sleep improvement of each intervention protocol are listed in Table 3.

\section{Earplugs/earmuffs}

Three controlled clinical trials [27,50,51] claimed that earplugs or earmuffs generally have a positive effect on patients' sleep in hospitals. A study by Zahr and Raversay [50] involved the behavioural and physiological responses of 30 premature infants to noise reduction by earmuffs. When the infants wore the earmuffs, the noise level was significantly decreased by 7 to $12 \mathrm{~dB}$, and their average oxygen saturation levels were higher and more stable than those of the infants without earmuffs. In Wallace and colleagues' pilot study [51], six healthy subjects were exposed to simulated ICU noise to evaluate the effect of earplugs on sleep measures. The use of earplugs was found to result in a significant increase in the REM sleep measured by polysomnography. Richardson and colleagues [27] undertook the first study to determine the combined impact of two interventions, earplug and eye mask, on the sleep experience of patients. Longer periods of sleep were successfully achieved for the patients of the intervention group at a very cost-effective price (£2.50 each).

\section{Behavioural modification}

Behavioural modification is a treatment approach, based on the principles of operant conditioning, that replaces un- 
Table 2

\section{Effectiveness of noise reduction strategies in intensive care units}

\begin{tabular}{|c|c|c|c|c|c|}
\hline $\begin{array}{l}\text { Author and } \\
\text { year published }\end{array}$ & Method & Participants & Setting & Intervention & Outcome \\
\hline $\begin{array}{l}\text { Zahr and } \\
\text { Traversay, } \\
1995[50]\end{array}$ & Controlled clinical trial & 30 premature infants & NICU in USA & Earmuffs & Improve sleep by $39.0 \%$ \\
\hline $\begin{array}{l}\text { Wallace } \\
\text { et al., } \\
1999 \text { [51] }\end{array}$ & $\begin{array}{l}\text { Controlled clinical trial; } \\
\text { polysomnography }\end{array}$ & $\begin{array}{l}6 \text { healthy adult } \\
\text { subjects }\end{array}$ & Sleep Lab in USA & Earplugs & Improve sleep by $33.7 \%$ \\
\hline $\begin{array}{l}\text { Richardson } \\
\text { et al., } \\
2007 \text { [27] }\end{array}$ & $\begin{array}{l}\text { Controlled clinical trial; } \\
\text { patient self-report }\end{array}$ & 64 adult patients & CCU in UK & $\begin{array}{l}\text { Earplugs + } \\
\text { eye masks }\end{array}$ & Improve sleep by $10 \%$ \\
\hline $\begin{array}{l}\text { Mann et al., } \\
1986 \text { [53] }\end{array}$ & $\begin{array}{l}\text { Controlled clinical trial; } \\
\text { nurse observation }\end{array}$ & $\begin{array}{l}41 \text { premature } \\
\text { infants }\end{array}$ & $\begin{array}{l}\text { Newborn nursery } \\
\text { in UK }\end{array}$ & $\begin{array}{l}\text { Behaviour } \\
\text { modification }\end{array}$ & Improve sleep by $13.8 \%$ \\
\hline $\begin{array}{l}\text { Kahn et al., } \\
1998 \text { [54] }\end{array}$ & Noise monitoring & All the ICU staff & $\begin{array}{l}\text { Medical ICU in } \\
\text { USA }\end{array}$ & $\begin{array}{l}\text { Behaviour } \\
\text { modification }\end{array}$ & Decrease noise by $1.9 \mathrm{dBA}$ \\
\hline $\begin{array}{l}\text { Walder et al., } \\
2000 \text { [55] }\end{array}$ & $\begin{array}{l}\text { Nurse observation for } \\
\text { sleep; noise monitoring }\end{array}$ & $\begin{array}{l}17 \text { adult ICU } \\
\text { patients }\end{array}$ & $\begin{array}{l}\text { Surgical ICU in } \\
\text { Switzerland }\end{array}$ & $\begin{array}{l}\text { Behaviour } \\
\text { modification }\end{array}$ & Decrease noise by $3 \mathrm{dBA}$ \\
\hline $\begin{array}{l}\text { Olson et al., } \\
2001[56]\end{array}$ & $\begin{array}{l}\text { Controlled clinical trial; } \\
\text { nurse observation for } \\
\text { sleep; noise monitoring }\end{array}$ & $\begin{array}{l}843 \text { adult ICU } \\
\text { patients }\end{array}$ & $\begin{array}{l}\text { Neurocritical care } \\
\text { unit in USA }\end{array}$ & $\begin{array}{l}\text { Behaviour } \\
\text { modification }\end{array}$ & Improve sleep by $18.3 \%$ \\
\hline $\begin{array}{l}\text { Monsén and } \\
\text { Edéll-Gustafsson, } \\
2005 \text { [57] }\end{array}$ & $\begin{array}{l}\text { Controlled clinical trial; } \\
\text { noise monitoring; } \\
\text { documentation of sleep } \\
\text { disturbance factors }\end{array}$ & $\begin{array}{l}23 \text { adult ICU } \\
\text { patients }\end{array}$ & $\begin{array}{l}\text { Neurointensive care } \\
\text { unit in Sweden }\end{array}$ & $\begin{array}{l}\text { Behaviour } \\
\text { modification }\end{array}$ & Decrease noise by $1.9 \mathrm{dBA}$ \\
\hline $\begin{array}{l}\text { Gragert, } \\
1990[58]\end{array}$ & $\begin{array}{l}\text { Controlled clinical trial; } \\
\text { RCSQ; researcher } \\
\text { observation }\end{array}$ & $\begin{array}{l}40 \text { old ICU } \\
\text { patients }\end{array}$ & $\begin{array}{l}\text { Coronary care unit } \\
\text { in USA }\end{array}$ & $\begin{array}{l}\text { Sound } \\
\text { masking }\end{array}$ & Improve sleep by $22.9 \%$ \\
\hline $\begin{array}{l}\text { Williamson, } \\
1992 \text { [59] }\end{array}$ & $\begin{array}{l}\text { Controlled clinical trial; } \\
\text { RCSQ }\end{array}$ & 60 CABG patients & $\begin{array}{l}\text { A public hospital } \\
\text { in USA }\end{array}$ & $\begin{array}{l}\text { Sound } \\
\text { masking } \\
\text { (ocean sound) }\end{array}$ & Improve sleep by $37.5 \%$ \\
\hline $\begin{array}{l}\text { Stanchina } \\
\text { et al., } \\
2005 \text { [60] }\end{array}$ & Polysomnography & $\begin{array}{l}4 \text { healthy adult } \\
\text { subjects }\end{array}$ & $\begin{array}{l}\text { Sleep lab } \\
\text { in USA }\end{array}$ & $\begin{array}{l}\text { Sound } \\
\text { masking } \\
\text { (white noise) }\end{array}$ & Improve sleep by $67.6 \%$ \\
\hline $\begin{array}{l}\text { Johnson, } \\
2001 \text { [61] }\end{array}$ & Noise monitoring & $\begin{array}{l}65 \text { premature } \\
\text { infants }\end{array}$ & NICU in USA & $\begin{array}{l}\text { Acoustic } \\
\text { material }\end{array}$ & Decrease noise by $3.3 \mathrm{dBA}$ \\
\hline $\begin{array}{l}\text { Blomkvist } \\
\text { et al., } \\
2005 \text { [48] }\end{array}$ & Noise monitoring & NA & Coronary ICU & $\begin{array}{l}\text { Acoustic } \\
\text { material }\end{array}$ & Decrease noise by $4 \mathrm{dBA}$ \\
\hline
\end{tabular}

CABG, coronary artery bypass graft; $\mathrm{CCU}$, critical care unit; ICU, intensive care unit; NA, not applicable; NICU, neonatal intensive care unit; RCSQ, Richard Campell sleep questionnaire.

desirable behaviours and reactions with more desirable ones through biofeedback and positive or negative reinforcement [52]. Two conditions are important for the selection of guidelines of behaviour modification: they must be easy to implement and they must not diminish the safety of the patients. Both noise and light are often the primary paired concerns of behaviour modification.

A randomised trial was accomplished by Mann and colleagues [53] to test the effect of night and day on infants in a newborn nursery. Besides turning off the radio, lights and covering the windows with thick and dark curtains, the behaviour of the staff and visitors were changed by the researchers to avoid generating unnecessary noise. Infants from the intervention group slept longer and gained more weight than those from the control nursery. Kahn and colleagues [54] concluded that many of the noises causing sound peaks over $80 \mathrm{dBA}$ were amenable to behaviour modification and that it was possible to reduce the noise levels in an ICU setting significantly through a comprehensive educational program of behaviour modification towards all the ICU staff. Walder and colleagues [55] implemented five 
Table 3

Comparison of the effectiveness of noise reduction strategies in intensive care units

\begin{tabular}{lcccc}
\hline & \multicolumn{3}{c}{ Intervention } \\
\cline { 2 - 5 } Outcome & Earplugs & Behavioural modification & Sound masking & Acoustic absorption \\
\hline Average noise level reduction & $\mathrm{NA}$ & $2.7 \mathrm{dBA}$ & $\mathrm{NA}$ & $3.6 \mathrm{dBA}$ \\
Average sleep improvement & $25.3 \%$ & $16.1 \%$ & $42.7 \%$ & $\mathrm{NA}$ \\
\hline
\end{tabular}

NA, not applicable.

guidelines to significantly lower the noise level and the number of alarms of hemodynamic monitoring in the surgical ICU. Noise reduction strategies included cutting down the intensity of the alarm sound and talking, and switching off the phone, television and radio. A "quiet time" (2 to $4 \mathrm{am}, 2$ to $4 \mathrm{pm}$ ) protocol was carried out in Olson and colleagues' study [56] to promote sleep in a large sample size in neurocritical care units. The increase in sleep behaviour was associated with decreased sound and light levels achieved during the quiet time. Patients observed during the intervention period were 1.6 times more likely to be asleep during the quiet time than were patients observed during the control period $(p<0.001)$. Monsén and Edéll-Gustafsson [57] introduced non-disturbance periods during afternoon and night, and changed nursing and medical routines, which resulted in reduced sleep disturbance factors and partly reduced noise levels in the neonatal ICU.

\section{Sound masking}

The sound masking system is often used to increase speech privacy and to minimize distractions from other sounds. The system is being introduced to hospitals while patient confidentiality is becoming more of an issue where responsible handling of personal details forms an essential part of a data protection policy. Limited case studies have also shown that using the systems in hospital wards could improve patient satisfaction [58-60]. In Gragert's study [58] the masking signal was proved to be an effective intervention and should be considered a viable method of enhancing the sleep quality of patients in noisy ICU environments. Patients with sound masking intervention believed that they slept better and that it was quieter than in the control group. Williamson [59] investigated the influence of ocean sounds (white noise) on the night sleep pattern of postoperative coronary artery bypass graft patients after being transferred from an ICU. The group receiving ocean sounds reported higher scores in sleep depth, awakening, return to sleep, quality of sleep, and total sleep scores, indicating better sleep than the controlled group. The study by Stanchina and colleagues [60] suggested that white noise increased arousal thresholds in healthy individuals exposed to recorded ICU noise. The change in sound from baseline to peak, rather than the peak sound level, determined whether an arousal occurred. From Table 3 it can be seen that sound masking has the most significant effect in promoting ICU patients' sleep, producing an improvement of $42.7 \%$.

\section{Acoustic absorbers}

Johnson [61] tested the effect of acoustic foams on the level of noise inside the incubator and examined neonatal response behaviours to changes in environmental noise. Acoustic foam pieces were placed in each of four corners of the incubator. The noise was reduced by $3.3 \mathrm{dBA}$ inside the incubator. In a study by Blomkvist and colleagues [48], after the replacement of the ceiling tiles the noise level was reduced by $4 \mathrm{~dB}$.

\section{Limitation of previous studies and directions for future work}

Previous studies, especially in medical sectors, have mainly been based on simple measurements of sound levels, whereas the influence of other room acoustic conditions, such as reverberation and reflection patterns, have not been paid enough attention. The sound level based approach has many limitations, even though different kinds of noise reduction protocols have been implemented and their effectiveness in improving patients' sleep has been demonstrated. Further research including other sound characteristics is required.

Besides noise, many other factors - for instance, light, medication and pain - would all contribute to the disturbed sleep of ICU patients. Some arousals may even mistakenly be attributed to noise [62]. However, research on the relative influence and the combined effects of those factors has been limited and this should be pursued in the future.

There has been very little research on the influences of acoustic conditions on healthcare staff. The patients are the centre of every hospital; however, the degree of staff satisfaction with the working environment directly affects working efficiency, enthusiasm and the quality of care provided.

No study has been found to compare noise conditions in different types of ICUs, for example, respiratory ICU, pediatric ICU, neonatal ICU, cardiac ICU, medical ICU, surgical ICU, and neuro ICU. 


\section{Conclusion}

Based on a number of original papers, the impact of noise on patients' sleep and the effectiveness of noise reduction strategies in ICUs have been reviewed. These have shown: noise is just one of a number of factors that may disrupt the sleep of patients on the ICU; staff conversation and alarms are generally regarded as the most disturbing noises for patients' sleep in ICUs; no research has been done on the relationships between ICU patients' sleep quality and the other room acoustic parameters besides sound level; and there are generally four interventions for sleep improvement, including earplugs, behavioural modification, sound masking, and acoustic absorption. Sound-absorbing treatment is a relatively effective noise reduction strategy, whereas sound masking appears to be the most effective technique for improving sleep.

There are some limitations of the existing studies, including the lack of attention to other room acoustic conditions in addition to sound level, the combined effects of different sleep disturbing factors, and the effects of noise on staff. For future research, there should be close collaboration between medical researchers and acousticians to examine the different characteristics of sound.

\section{Competing interests}

The authors declare that they have no competing interests.

\section{References}

1. Kang J: Urban Sound Environment. London: Taylor and Francis; 2006.

2. Snyder-Halpern R: The effect of critical care unit noise on patient sleep cycles. Crit Care Q 1985, 4:41-51.

3. Thomas KA, Martin PA: NICU sound environment and the potential problems for caregivers. J Perinatol 2000, 20(Suppl 1):94-99.

4. Tomei F, Papaleo B, Baccolo TP, Persechino B, Spano G, Rosati MV: Noise and gastric secretion. Am J Ind Med 1994, 26:367372.

5. Falk SA, Woods N: Hospital noise: levels and potential health hazards. New Engl J Med 1973, 289:774-781.

6. Wysocki A: The effect of intermittent noise exposure on wound healing. Adv Wound Care 1996, 9:35-39.

7. Nurminen T: Female noise exposure, shift work and reproduction. J Occup Environ Med 1995, 37:945-950.

8. Berglund B, Lindvall T, Schwela DH: Guidelines for Community Noise. Geneva: World Health Organization; 1999.

9. Busch-Vishniac IJ, West JE, Barnhill C, Hunter T, Orellana D, Chivukula R: Noise levels in Johns Hopkins Hospital. J Acoust Soc Am 2005, 118:3629-3645.

10. Al-Samsam RH, Cullen P: Sleep and adverse environmental factors in sedated mechanically ventilated pediatric intensive care patients. Pediatr Crit Care Med 2005, 6:562-567.

11. Saletu B, Grunberger J: Traffic noise-induced sleep disturbances and their correction by an anxiolytic sedative, OX-373. Neuropsychobiology 1981, 7:302-314.

12. Cluydts R, De Roeck J, Cosyns P, LaCante P: Antagonizing the effects of experimentally induced sleep disturbance in healthy volunteers toy lormetazepam and zolpidem. J Clin Psychopharm 1995, 15:132-137.

13. Kawada T, Kiryu Y, Sasazawa $Y$, Suzuki, S: Instantaneous change in transient shift of sleep stage in response to passing truck noise. Environ H Preventive Med 1998, 3:1-5.

14. Franssen EAM, Van Wiechen CMAG, Nagelkerke NJD, Lebret E: Aircraft noise around a large international airport and its impact on general health and medication use. Occup Environ Med 2004, 61:405-413.
15. Basner M, Samel A, Isermann U: Aircraft noise effects on sleep: application of the results of a large polysomnographic field study. J Acoust Soc Am 2006, 119:2772-2784.

16. Marks A, Griefahn B, Basner M: Event-related awakenings caused by nocturnal transportation noise. Noise Control Eng J 2008, 56:52-62.

17. Jones J, Hoggart B, Withey, J: What the patients say: a study of reactions to an intensive care unit. Intens Care Med 1979, 5: 89-92.

18. Freedman NS, Kotzer N, Schwab RJ: Patient perception of sleep quality and etiology of sleep disruption in the intensive care unit. Am J Resp Crit Care 1999, 159:1155-1162.

19. Meyer TJ, Eveloff SE, Bauer MS, Schwartz WA, Hill NS, Millman RP: Adverse environmental conditions in the respiratory and medical ICU settings. Chest 1994, 105:1211-1216.

20. Freedman NS, Gazendam J, Levan L, Pack Al, Schwab RJ: Abnormal sleep/wake cycles and the effect of environmental noise on sleep disruption in the intensive care unit. $A m J$ Resp Crit Care 2001, 163:451-457.

21. Frisk U, Nordstrom G: Patients' sleep in an intensive care unit Patients' and nurses' perception. Intens Crit Care Nurs 2003, 19:342-349.

22. Gabor JY, Cooper AB, Crombach SA: Contribution of the intensive care unit environment to sleep disruption in mechanically ventilated patients and healthy subjects. Am J Resp Crit Care 2003, 167:708-715.

23. Ugras GA, Oztekin SD: Patient perception of environmental and nursing factors contributing to sleep disturbances in a neurosurgical intensive care unit. Tohoku J Exp Med 2007, 212:299-308.

24. Hilton BA: Quantity and quality of patients sleep and sleepdisturbing factors in a respiratory intensive care unit. $J A d v$ Nurs 1976, 1:453-468.

25. Aaron JN, Carlisle CC, Carskadon MA: Environmental noise as a cause of sleep disruption in an intermediate respiratory care unit. Sleep 1996, 19:707-710.

26. Cureton-Lane RA, Fontaine DK: Sleep in the pediatric ICU: an empirical investigation. Am J Crit Care 1997, 6:56-63.

27. Richardson A, Allsop M, Coghill E, Turnock C: Earplugs and eye masks: do they improve critical care patients' sleep? Nurs Crit Care 2007, 12:278-286.

28. Hweidi IM: Jordanian patients' perception of stressors in critical care units: a questionnaire survey. Int J Nurs Stud 2007, 44:227-235.

29. Aurell J, Elmqvist D: Sleep in the surgical intensive care unit: continuous polygraphic recording of sleep in nine patients receiving postoperative care. Brit Med J 1985, 290:1029-1032.

30. Gabor JY, Cooper AB, Crombach SA, Lee B, Kadikar N, Bettger $\mathrm{HE}$, Hanly PJ: Contribution of the intensive care unit environment to sleep disruption in mechanically ventilated patients and healthy subjects. Am J Resp Crit Care 2003, 167:708-715.

31. Cooper AB, Thornley KS, Young GB, Slutsky AS, Stewart TE, Hanly PJ: Sleep in critically ill patients requiring mechanical ventilation. Chest 2000, 117:809-818.

32. McNicoll L, Pisani MA, Zhang Y, Ely EW, Siegel MD, Inouye SK: Delirium in the intensive care unit: occurrence and clinical course in older patients. J Am Geriatr Soc 2003, 51:591-598.

33. Ely EW, Shintani A, Truman B, Speroff T, Gordon SM, Harrell FE, Jr, Inouye SK, Bernard GR, Dittus RS: Delirium as a predictor of mortality in mechanically ventilated patients in the intensive care unit. J Am Med Assoc 2004, 291:1753-1762.

34. Dinges DF, Douglas SD, Zaugg L, Campbell DE, McMann JM, Whitehouse WG, Orne EC, Kapoor SC, Icaza E, Orne MT: Leukocytosis and natural killer cell function parallel neurobehavioral fatigue induced by $\mathbf{6 4}$ hours of sleep deprivation. $J$ Clin Invest 1994, 93:1930-1939.

35. Benca RM, Quintas J: Sleep and host defenses: a review. Sleep 1997, 20:1027-1037.

36. Palmblad J, Petrini B, Wasserman J, Akerstedt T: Lymphocyte and granulocyte reactions during sleep deprivation. Psychosom Med 1979, 41:273-278.

37. Brown R, Pang G, Husband AJ, King MG: Suppression of immunity to influenza virus infection in the respiratory tract following sleep disturbance. Region Immunol 1989, 2:321-325.

38. Moldofsky H, Lue FA, Davidson JR, Gorczynski R: Effects of sleep deprivation on human immune functions. J Federation Am Soc Exp Biol 1989, 3:1972-1977. 
39. Vgontzas AN, Zoumakis E, Bixler EO, Lin HM, Follett $H$, Kales A, Chrousos GP: Adverse effects of modest sleep restriction on sleepiness, performance, and inflammatory cytokines. $J$ Clin Endocr Metab 2004, 89:2119-2126.

40. Boyum A, Wiik P, Gustavsson E, Veiby OP, Reseland J, Haugen $\mathrm{AH}$, Opstad PK: The effect of strenuous exercise, calorie deficiency and sleep deprivation on white blood cells, plasma immunoglobulins and cytokines. Scand J Immunol 1996, 43: 228-235.

41. Younes $M$ : Apnea following mechanical ventilation may not be caused by neuromechanical influences. Am J Resp Crit Care 2001, 163:1298-1301.

42. Hansell HN: The behavioral effects of noise on man: the patient with "intensive care unit psychosis". Heart Lung 1984, 13:59-65.

43. MacKenzie DJ, Galbrun L: Noise levels and noise sources in acute care hospital wards. Build Serv Eng Res Technol 2007, 28:117-131.

44. Chambrin MC: Alarms in the intensive care unit: how can the number of false alarms be reduced. Crit Care 2001, 5:184188.

45. Busch-Vishniac IJ, West JE, Barnhill C, Hunter T, Orellana D, Chivukula R: Noise levels in Johns Hopkins Hospital. J Acoust Soc $A m$ 2005, 118:3629-3645.

46. Livera MD, Priya B, Ramesh A, Suman Rao PN, Srilakshmi V Nagapoornima M, Ramakrishnan AG, Dominic M: Spectral analysis of noise in the neonatal intensive care unit. Indian $J$ Pediatr 2008, 75:217-222.

47. Ryherd EE, Persson Waye K, Ljungkvist L: Characterizing noise and perceived work environment in a neurological intensive care unit. J Acoust Soc Am 2008, 123:747-756.

48. Blomkvist V, Eriksen CA, Theorell T: Acoustics and psychosocial environment in intensive coronary care. Occup Environ Med 2005, 62:e1.

49. MacLeod M, Dunn J, Busch-Vishniac IJ, West JE, Reedy A: Quieting Weinberg 5C: A case study in hospital noise control. J Acoust Soc Am 2007, 121:3501-3508

50. Zahr LK, DE Traversay: Premature infant responses to noise reduction by earmuffs: effects on behavioral and physiologic measures. J Perinatol 1995, 15:448-455.

51. Wallace CJ, Robins J, Alvord LS, Walker JM: The effect of earplugs on sleep measures during exposure to simulated intensive care unit noise. Am J Crit Care 1999, 8:210-219.

52. Miltenberger RG: Behavior Modification: Principles and Procedures. Wadsworth/Thomson Learning; 2003.

53. Mann NP, Haddow R, Stokes L, Goodley S, Rutter N: Effect of night and day on preterm infants in a newborn nursery: randomised trial. Br Med J (Clin Res Ed) 1986, 293:1265-1267.

54. Kahn DM, Cook TE, Carlisle CC, Nelson DL, Kramer NR, Millman $\mathrm{RP}$ : Identification and modification of environmental noise in an ICU setting. Chest 1998, 114:535-540.

55. Walder B, Francioli D, Meyer JJ: Effects of guidelines implementation in a surgical intensive care unit to control nighttime light and noise levels. Crit Care Med 2000, 28:2242-2247.

56. Olson DM, Borel CO, Laskowitz DT, Moore DT, McConnell ES: Quiet time: a nursing intervention to promote sleep in neurocritical care units. Am J Crit Care 2001, 10:74-78.

57. Monsén MG, Edéll-Gustafsson UM: Noise and sleep disturbance factors before and after implementation of a behavioural modification programme. Intensive Crit Care Nurs 2005, 21:208-219.

58. Gragert MD: The use of a masking signal to enhance the sleep of men and women 65 years of age and older in the critical care environment. PhD Thesis. The University of Texas at Austin; 1990

59. Williamson JW: The effects of ocean sounds on sleep after coronary artery bypass graft surgery. Am J Crit Care 1992, 1: 91-97.

60. Stanchina ML, Abu-Hijleh M, Chaudhry BK: The influence of white noise on sleep in subjects exposed to ICU noise. Sleep Med 2005, 6:423-428.

61. Johnson AN: Neonatal response to control of noise inside the incubator. Pediatr Nurs 2001, 27:600-605.

62. Drouot X, Cabello B, d'Ortho MP, Brochard L: Sleep in the intensive care unit. Sleep Med Rev, 12:391-403. 